\title{
Os indicadores de saúde e a contratualização
}

Raquel Braga*

$\mathrm{N}$ o último editorial da Revista Portuguesa de Medicina Geral e Familiar, abordou-se a desaceleração do processo de reforma dos Cuidados de Saúde Primários ${ }^{1}$ e foram apresentados argumentos que apoiam o seu desenvolvimento e implementação. No entanto, como em qualquer outro processo em curso, há factores que necessitam de reflexão, melhoria e intervenção.

Os médicos de família portugueses podem orgulhar-se de terem idealizado uma reforma completa e complexa dos Cuidados de Saúde Primários. Ela contempla, entre outras características, a autonomia organizativa das Unidades de Saúde Familiar (embora cada vez mais relativa...), a existência de um compromisso assistencial (que garante maior cobertura populacional à custa da ampliação das listas de utentes) e a contratualização de objectivos ou metas a atingir (em relação ao acesso, desempenho assistencial, qualidade percepcionada e desempenho económico), mas que nem sempre tem decorrido nos prazos e formatos previstos.

Muitos são os países que ainda não atingiram semelhante grau de sofisticação e de objectivação da qualidade de cuidados que se propõem prestar. A definição de indicadores de saúde, a sua contratualização e a sua avaliação evidenciam um nível de envolvimento e de responsabilização notáveis por parte da tutela, dos profissionais de saúde e da população e reflectem um desejo de garantia e melhoria dos cuidados prestados.

No entanto, os indicadores de saúde até agora propostos entre nós, sofrem de problemas de dimensão, relevância e cálculo. As metas propostas aproximam-se de valores cada vez mais próximos dos $100 \%$, como acontece com os indicadores de desempenho assistencial, apenas porque isso é o que parece lógico aos gestores, seguramente sem formação do ponto de vista clínico. Estes valores, gradualmente mais elevados ano após ano, pretendem reflectir uma progressão da

*Directora da Revista Portuguesa de Medicina Geral e Familiar melhoria da qualidade de cuidados prestados, mas estão desfasados de um enquadramento clínico e assistencial realista, das circunstâncias locais, dos contratempos pessoais e dos sistemas de saúde reais.

No entanto, o cálculo das metas a contratualizar deveria ser cuidadosamente baseado na evidência científica e ter em conta o contexto local, para além da caracterização das necessidades detectadas e expressas da população. ${ }^{2} \mathrm{~A}$ abrangência e a diversidade dos indicadores contratualizados deveriam, igualmente, ter em conta a prevalência dos problemas de saúde que afectam a população, bem como a importância e a frequência dos motivos que trazem os doentes à consulta. Por último, seria de esperar que a quantidade de indicadores de saúde sofresse uma evolução, no sentido de um aumento na diversidade dos problemas de saúde incluídos, até níveis virtualmente impossíveis de «tomar atenção» ou «dar conta de» por parte dos prestadores de cuidados de saúde. Dessa forma, seria atingida a Qualidade, no sentido de ela estar garantida, mesmo sem ser avaliada ou monitorizada, o que significa que seria tudo bem feito, sem necessidade de estar alguém «a observar».

Apesar de sofrerem de problemas, como a focalização de cuidados (que pode conduzir a um afunilamento da actividade médica) ${ }^{3} \mathrm{e}$ de se centrarem em normas de actuação arbitrárias, em vez de em resultados que interessam ao doente (Patient oriented evidence that matters - POEM) a existência de indicadores orienta a actuação e responsabiliza as equipas de saúde em prol de resultados objectiváveis. O trabalho a efectuar para garantir bons resultados e ganhos em saúde não é, neste momento, aumentar a fasquia destes indicadores indefinidamente, (até porque em algumas Unidades de Saúde isso já nem é possível!) mas sim trabalhar no sentido da criação de outros indicadores, dirigidos a reais ganhos em saúde e que promovam uma medicina centrada na pessoa mais do que uma medicina centrada nos indicadores. ${ }^{3}$ 
O Plano Nacional de Saúde 2012 -2016 é um documento abrangente que prevê indicadores que reflectem o estado de Saúde e o desempenho do Sistema de Saúde.

Discrimina indicadores de estado de saúde (que contemplam a mortalidade, morbilidade, incapacidade e bem-estar), determinantes de saúde (que possibilitam o conhecimento sobre os factores para os quais há evidência cientifica quanto à influência sobre o estado de saúde e da utilização dos cuidados de saúde), indicadores de desempenho do sistema de saúde (que reflectem a aceitabilidade, acesso, qualidade, capacitação, integração de cuidados, efectividade, eficiência e segurança) e os indicadores de contexto (que contêm medidas de caracterização que permitem, por ajustamento, comparar populações distintas). ${ }^{4}$

Estes últimos, talvez os mais dificeis de definir e monitorizar, vêm ao encontro da necessidade sentida de olhar e planificar cuidados de saúde para cada realidade local, de forma personalizada, fugindo a um modelo de prestação de cuidados e de contratualização uniforme que se revela desfasado das necessidades e características particulares de cada população.

Para garantir a melhoria dos cuidados a prestar, é fundamental ter em conta as necessidades expressas pelo doente, para além das detectadas pelos Planos de Acção e possibilitar, do ponto de vista clínico, tempo na consulta que permita dirigir a atenção ao fundamental: ouvir a pessoa que está diante de nós.

A comunicação médica, baseada num modelo centrado no paciente, para a qual os Médicos de Família são especificamente treinados, necessita de tempo e de focalização de atenção na pessoa e nos seus problemas. É uma competência específica, à qual raramente outras especialidades dedicam treino ou atenção e que constitui, em si mesma, uma ferramenta de trabalho e um meio diagnóstico e terapêutico custo-efectivo. Todos os Médicos de Família têm a experiência frequente de ouvirem as pessoas dizer, ao sair do consultório, «Fez-me bem desabafar!» ou «Fez-me bem falar consigo!».

O médico como medicamento, a relação terapêutica, não pode ser posta em causa por outras tarefas. $\mathrm{O}$ médico deve ser o continente das angústias e necessidades dos doentes e, para isso, deve ter o tempo suficiente para as entender e permitir a posterior intervenção terapêutica adequada.
Se persistir a focalização da prática clínica em indicadores para os quais tenhamos de canalizar a atenção, desdobrando os nossos gestos em tarefas maquinais e registos desgastantes e distraindo-nos da pessoa que está diante de nós, perdemos o fundamental.

O âmago da acção do Médico de Família é olhar a pessoa na sua globalidade biopsicossocial, triar, isolar, diagnosticar e intervir, prevenindo ou solucionando problemas. Não se restringe a verificar checklists de tarefas desprovidas de fundamentação ou inoportunas, face às necessidades prementes demonstradas pelas pessoas que nos solicitam ajuda.

As propostas de consultas focalizadas em doenças ou a assunção de actividades direccionadas para patologias (como a consulta de hipocoagulação, a consulta de desabituação tabágica e a consulta de pé diabético) que estão a ser atribuídas às Unidades de Saúde sob a capa da contenção de custos, desvirtuam o âmago dos cuidados que devemos prestar.

Este tipo de actividades, propostas inicialmente como carteira adicional de serviços, deverão manter-se como tal e ser assumidas voluntariamente, por motivação e gosto pessoal, assegurada a aquisição da necessária formação. O tempo que lhes é dispensado não poderá ser roubado ao tempo consagrado a tarefas que só um especialista em Medicina Geral e Familiar pode providenciar. Estas tarefas estão devidamente contratualizadas e fazem parte do compromisso assistencial assumido pelas Unidades de Saúde, constituindo a carteira básica de serviços.

As competências específicas de um especialista em Medicina Geral e Familiar, que constituem o seu «core business» e são sua atribuição específica, não podem ser praticadas por outros médicos. Da mesma forma, este princípio deve ser salvaguardado deixando às outras especialidades a tarefa de se ocuparem das áreas para as quais têm competências específicas. Mesmo que estas sejam empurradas para o âmbito da consulta de Medicina Geral e Familiar sob o pretexto de minorar custos, o carácter generalista e integrador da actividade do Médico de Família, aliado à sobrecarga com um número crescente de utentes, visando o cumprimento do compromisso assistencial, não se compactua com maior elasticidade.

Não se trata de um problema de competências ou de falta delas e não se trata de um problema de falta de 
vontade; trata-se apenas de não sobrar espaço nem tempo aos Médicos de Família para abarcarem mais do que o muito que já os ocupa e que mais ninguém pode ou deve fazer em vez deles.

\section{REFERÊNCIAS BIBLIOGRÁFICAS}

1. Braga R. A desaceleração do processo de Reforma dos Cuidados de Saúde Primários. Rev Port Med Geral Fam 2013 Jul-Ago; 29 (4): 21820.

2. Dias CM, Freitas M, Briz T. Indicadores de saúde: uma visão de saúde pública, com interesse em Medicina Geral e Familiar. Rev Port Clin
Geral 2007 Jul-Ago; 23 (4): 439-50.

3. Melo M Sousa JC. Os indicadores de desempenho contratualizados com as USF: um ponto da situação no actual momento da reforma. Rev Port Clin Geral 2011 Jan-Fev; 27 (1): 28-34.

4. Plano Nacional de Saúde 2012-2016. Disponível em: http://pns.dgs.pt/ pns-2012-2016/ [acedido em 01/10/2013].

\section{CONFLITO DE INTERESSES}

A autora declara trabalhar numa USF em Modelo A.

\section{ENDEREÇO PARA CORRESPONDÊNCIA}

director@rpmgf.pt 